\title{
WAP four-disulfide core domain protein 2 gene(WFDC2) is a target of estrogen in ovarian cancer cells
}

\author{
Yao Chen ${ }^{1}$, Suihai Wang ${ }^{1}$, Tiancai Liu', Yingsong Wu', Ji-Liang $\mathrm{Li}^{1,2^{*}}$ and Ming $\mathrm{Li}^{\mathrm{i}^{*}}$
}

\begin{abstract}
Background: WAP four-disulfide core domain protein 2 (WFDC2) shows a tumor-restricted upregulated pattern of expression in ovarian cancer.

Methods: We investigated the role of estradiol (E2) on cell growth in estrogen-sensitive or estrogen-insensitive ovarian cancer cell lines. Real-time (RT)-PCR and western blotting were used to examine the expression of WFDC2 at RNA and protein levels. Growth traits of cells transfected with WFDC2-shRNA or blank control were assessed using MMT arrays. Cell apoptosis was analyzed using annexin V-FITC/PI and flow cytometry. Estrogen receptor expression was evaluated using RT-PCR and flow cytometry. Apoptosis-related proteins induced by E2 directly and indirectly were determined using an antibody array comparing cells transfected with WFDC2- shRNA or a blank control.

Results: High-dose $(625 \mathrm{ng} / \mathrm{ml})$ E2 increased the expression of WFDC2 in HO8910 cells at both the mRNA and protein levels. However, E2 had no effect on WFDC2 expression in estrogen-insensitive SKOV3 cells. Of interest, knockdown of WFDC2 enabled a considerable estrogen response in SKOV3 cells in terms of proliferation, similar to estrogen-responsive HO8910 cells. This transformation of SKOV3 cells into an estrogen-responsive phenotype was accompanied by upregulation of estrogen receptor beta (ERß) and an effect on cell apoptosis under E2 treatment by regulating genes related to cell proliferation and apoptosis.
\end{abstract}

Conclusions: We postulate that increased WFDC2 expression plays an important role in altering the estrogen pathway in ovarian cancer, and the identification of WFDC2 as a new player in endocrine-related cancer encourages further studies on the significance of this gene in cancer development and therapy.

Keywords: WFDC2, Ovarian cancer, Estrogen, Cell proliferation, Apoptosis

\section{Background}

Ovarian cancer is one of the most common cancers among women and the leading cause of death from gynecological malignancies in the world $[1,2]$. The underlying causes of ovarian cancer are poorly understood and largely untested, but estrogen, as a major steroidal product of the ovary, has been shown to be associated with increased ovarian cancer risk in estrogen receptor (ER)-expressing cells [3-5]. Hormone replacement therapy (HRT) has been widely used in women

\footnotetext{
*Correspondence: 23473820@qq.com; woailanmi@sina.com

${ }^{1}$ School of Biotechnology, Southern Medical University, 1023 Shatainan Road, Guangzhou 510515, China

Full list of author information is available at the end of the article
}

with estrogen-withdrawal syndromes. Estrogen has been associated with an increased ovarian cancer risk and it can promote tumor growth and cell proliferation in ERexpressing cell lines. The main biological functions of estrogen are manifested through transcriptional activation of the ligand-dependent ERs, ER $\alpha$ and $\operatorname{ER} \beta[3,6]$. More than two-thirds of ovarian cancer patients are positive for ER $\alpha$ [6-8]. The activation of ER results in an altered expression of its direct transcriptional targets, thereby affecting a series of downstream secondary biological activities. However, the regulatory effects of estrogen on the behavior of ovarian tumor cells involves a complex signaling network and the underlying mechanisms are still not fully understood. Therefore, 
identification of novel targets regulated by estrogen will be very important to clarify the specific impact of estrogen on ovarian tumor growth and facilitate the development of new diagnostic and therapeutic markers $[4,5,9]$.

In recent years, a number of studies have shown that numerous estrogen-responsive genes, including insulinlike growth factor binding protein (IGFBP) family members (IGFBP3, IGFBP4 and IGFBP5), trefoil factor (TFF) family members (TFF1 and TFF3), and TNF receptorassociated protein 1 (TRAP1) among others, affect the growth and development of ovarian cancer [10, 11]. Genomic analysis of ovarian cancer identified gene amplification of the WFDC2 gene (that encodes the human epididymis protein $4(H E 4)$ ) and the whey acidic protein gene loci in a large proportion of epithelial ovarian cancers $[12,13]$. HE4 exhibits a tumor-restricted, upregulated pattern of expression in ovarian cancer, making it a potential marker [12, 14, 15]. The previous work has shown a direct linkage between HE4 expression and cell proliferation; however the molecular mechanisms are still unclear $[12,16]$. To date, the majority of studies have focused on the potential value of HE4 as a diagnostic using various serologic tests, but very little attention has been paid to the role of HE4 in tumor development of ovarian cancer $[12,14,17]$.

The WFDC2 gene is located on human chromosome 20q12-13.1, a region that includes 14 genes that encode proteins with a WAP-type four-disulfide core (WFDC) domain $[14,17]$. Two of the best-studied members of the WAP gene family are SLPI and PI3 (that encodes for elafin), both having antiproteinase activity. They are coexpressed with WFDC2 and involved in cancer development or progression in various carcinomas affected by sex hormones $[9,14,18]$. So we could not help to speculate that WFDC2 might also play some role in the estrogen-sensitive ovarian cancers.

As a cancer-specific gene, several hormone-response elements were found within the WFDC2 promoter, including an estrogen response element (ERE) and RORA, which may be attributed to HE4 upregulation in ovarian cancer and ovarian cancer specificity [19]. The amount of HE4 in blood samples was significantly different between follicular (FP) and ovulatory (OP) phases of the hormonal cycle, being lower in the FP than in the OP [20]. The menstrual cycle phase-dependent variability indicated that WFDC2 expression might be affected by the menstrual cycle of women. These results suggested that WFDC2 might be an estrogen response gene, and play important roles in the cell proliferation and malignant transformation of ovarian cancer.

In this study, we investigated the regulatory effects of estrogen and estrogen antagonist on WFDC2 gene expression in estrogen sensitive HO8910 cells and estrogen insensitive SKOV3 cells, with the aim to determine whether WFDC2 is an estrogen-responsive gene. And then, we transfected these cells with short hairpin RNA (shRNA) against WFDC2, and investigated the effect of WFDC2 silencing on cell proliferation, its interaction with ER and its effect on ER-mediated signaling.

\section{Methods}

\section{Cells and treatments}

The cell bank of the Chinese Academy of Sciences (Shanghai, China) supplied the human ovarian cancer cell lines, HO8910 and SKOV3 (American Type Culture Collection (ATCC), Manassas, VA, USA). Cells were maintained in minimal essential medium supplemented with $10 \%(v / v)$ fetal bovine serum (FBS) at $37^{\circ} \mathrm{C}$ in an atmosphere of $95 \%$ air, $5 \% \mathrm{CO}_{2}$. The ligand $17 \beta$ estradiol (E2) and the selective ER modulator (SERM), tamoxifen (TAM), were purchased from Sigma-Aldrich (St Louis, MO, USA). Before the cells were treated with the ligands, the medium was replaced with minimal essential medium supplemented with $0.5 \%$ FBS. Cells were treated with different concentrations of E2 $(5,25$, $125,625$ and $1250 \mathrm{ng} / \mathrm{ml})$, and TAM $(100 \mathrm{ng} / \mathrm{ml})$, for $24 \mathrm{~h}$ prior to quantitative real-time PCR (QPCR) and $48 \mathrm{~h}$ prior to western blotting and protein array analysis.

\section{RNA extraction and QPCR}

Total RNA was isolated following the manufacturer's instructions (PrimeScript 1st Strand cDNA Synthesis Kit, TAKARA). Reverse transcription was also performed following the manufacturer's instructions in a total volume of $20 \mu \mathrm{l}$ using an oligo-dT primer and $1 \mu \mathrm{g}$ of total RNA. Each primer set was designed using Primer Express software v3.0 to flank an intron to prevent the amplification of genomic DNA. $\beta$-actin was used to evaluate the efficiency and variability of the reverse transcription step. CDNA samples $(0.1 \mu \mathrm{g})$ were amplified using the SYBR Green PCR Master Mix (TAKARA) under conditions recommended by the manufacturer: (a) pre-incubation at $95{ }^{\circ} \mathrm{C}$ for $30 \mathrm{~s}$; (b) 40 PCR cycles of $95{ }^{\circ} \mathrm{C}$ for $5 \mathrm{~s}, 55^{\circ} \mathrm{C}$ for $30 \mathrm{~s}$, and $72{ }^{\circ} \mathrm{C}$ for $34 \mathrm{~s}$. Samples were assayed in duplicate using the ABI Prism 7500 detection system (Perkin Elmer Applied Biosystems). The relative quantification number was then calculated by subtracting the average CT from the corresponding average $\mathrm{CT}$ for $\beta$-actin.

\section{Western blotting}

Total protein was extracted using sonication in radioimmunoprecipitation assay (RIPA) buffer $(50 \mathrm{mM}$ Tris$\mathrm{HCl} \mathrm{pH} \mathrm{7.5,} 150 \mathrm{mM} \mathrm{NaCl}, 5 \mathrm{mM}$ EDTA, 0.5 \% Nonidet P-40, $5 \mathrm{mM}$ dithiothreitol, $10 \mathrm{mM} \mathrm{NaF}$, and protease inhibitor cocktail). One hundred micrograms of denatured protein was separated on an SDS-polyacrylamide gel and 
transferred to a Hybond membrane (Amersham, Germany), which was then blocked overnight in $5 \%$ skim milk in Tris-buffered saline with Tween 20 (TTBS, $10 \mathrm{mM}$ Tris- $\mathrm{HCl}, 150 \mathrm{mM} \mathrm{NaCl}, 0.1 \%$ Tween 20). For immunoblotting, the membrane was incubated for 15 min with the WFDC2 antibody. The membrane was rinsed with TTBS and incubated with anti-rabbit IgG conjugated to horseradish peroxidase (DAKO, USA, 1:1000) for $15 \mathrm{~min}$. All incubations were performed in a microwave oven to allow intermittent irradiation. Bands were visualized on an ImageQuant LAS4010 (GE Healthcare Life Science, USA) using ECL-Plus detection reagents (Santa Cruz, USA). Densitometric quantification of protein bands with GAPDH as an internal control was performed using Image $\mathrm{J}$ (NIH, USA).

\section{Gene silencing}

The WFDC2-specific shRNA sequence (5'-GCTCT CTGCCCAATGATAAGG-3') (based on the Gene Bank Accession No. NM_0006103.3) and its control sequence (5'-GTTCTCCGAACGTGTCACGT-3') were chemically synthesized and cloned into the pGLV-U6-GFP vector by Shanghai GenePharma Co. Ltd (Camsonne et al.). Lentiviruses, purchased from the same company, were transduced into the HO8910 cell line according to the manufacturer's instructions. For stable silencing of WFDC2, the transduced HO8910 cell line, named HO8910-209, was selected using puromycin. Puromycinresistant colonies were then picked, expanded and analyzed separately.

\section{Cell proliferation assays}

The in vitro proliferation assay was performed using the 3-(4, 5-dimethylthiazol-2-yl)-2, 5-diphenyltetrazolium bromide (MTT) assay following the manufacturer's instructions (Sigma). Briefly, 500 cells per well were plated in 96-well plates in triplicate. After a $24 \mathrm{~h}$ incubation, cells were serum-starved for $24 \mathrm{~h}$ and then treated with different concentrations of estrogen $(0,5,25,125,625$ and $1250 \mathrm{ng} / \mathrm{ml}$ ) or TAM for 6 days. At the indicated time, cell proliferation was determined by measurement of the absorbance values using the MTT assay method, and cell growth curves were then plotted.

\section{Flow cytometry}

Cells were trypsinized and washed three times with phosphate-buffered saline (PBS). Cells were then digested with $1 \%$ RNase at $37{ }^{\circ} \mathrm{C}$ for $30 \mathrm{~min}$ and stained with annexin V-FITC for $30 \mathrm{~min}$, followed by staining with propidium iodide (PI, Sigma, Shanghai, China) for 5 min at $4{ }^{\circ} \mathrm{C}$ for cell apoptotic analysis. The results were analyzed using WinMDI software with 10,000 events collected for each sample. Cell suspensions were also incubated with antibodies to ER $\alpha$ and ERß $\left(1 \mu \mathrm{g} / 1 \times 10^{6}\right.$ cells) for $30 \mathrm{~min}$ at $37^{\circ} \mathrm{C}$. Cells were then washed three times with PBS, and incubated with PE and an FITClabeled secondary antibody for $30 \mathrm{~min}$ at $37^{\circ} \mathrm{C}$. Cell suspensions were washed three times with PBS. Expression of ER $\alpha$ and ERß per 10000 cells was determined using flow cytometry.

\section{Annexin V-FITC/PI staining}

Apoptosis was evaluated using the Annexin V-FITC/PI Apoptosis Detection kit (BestBio, Shanghai, China) using fluorescence microscopy according to the manufacturer's instructions. Briefly, cells were grown onto a cover slide and incubated with E2 $(625 \mathrm{ng} / \mathrm{ml})$ for $24 \mathrm{~h}$. The adherent cells were washed twice with ice-cold PBS and stained with annexin V-FITC and PI for 15 min and examined under a light microscope equipped with appropriate filters. Apoptotic cells stained with annexin VFITC showed green fluorescence, and necrotic cells stained with both annexin V-FITC and PI produced red fluorescence as well as green fluorescence.

\section{Human antibody array for apoptotic-related proteins}

Apoptotic-related proteins induced by E2 directly and indirectly were determined using the RayBio ${ }^{\circ}$ LabelBased Human Antibody Array kit (RayBio ${ }^{\circ}$ Human Apoptosis Antibody array) (RayBiotech, Norcross, GA). Densitometric analysis was performed on a Kodak ImageStation 4000 M (Eastman Kodak Company, Rochester, NY) with background subtraction from spot edges following the manufacturer's instructions. Spot data were normalized to a positive control spot on each array.

\section{Statistics}

Microsoft Office Excel 2007 and the statistical software SPSS13.0 were used in data processing and the $t$-test was used in analyzing significance. $\mathrm{P}$ values $<0.05$ were considered statistically significant. Data were expressed as the mean $\pm \mathrm{SD}$ from at least three independent experiments.

\section{Results \\ High-dose E2 induces expression of WFDC2 in HO8910 cells}

To determine if HE4/WFDC2 is a downstream target of E2 signaling pathways, we induced the expression of the WFDC2 gene by adding E2 into the culture of HO8910 cells using a range of concentrations $(0,5,25,125,625$ and $1250 \mathrm{ng} / \mathrm{ml}$ ). The results indicated that the WFDC2 gene was upregulated only when cells were treated with a high dose of E2. The expression of WFDC2 at both mRNA and protein levels was increased with E2 from 125 to $1250 \mathrm{ng} / \mathrm{ml}$ as detected using QPCR $(P<0.05)$ (Fig. 1a) and western blotting $(P<0.05)$ (Fig. 1b). At a concentration of $625 \mathrm{ng} / \mathrm{ml}$, E2 increased the protein 

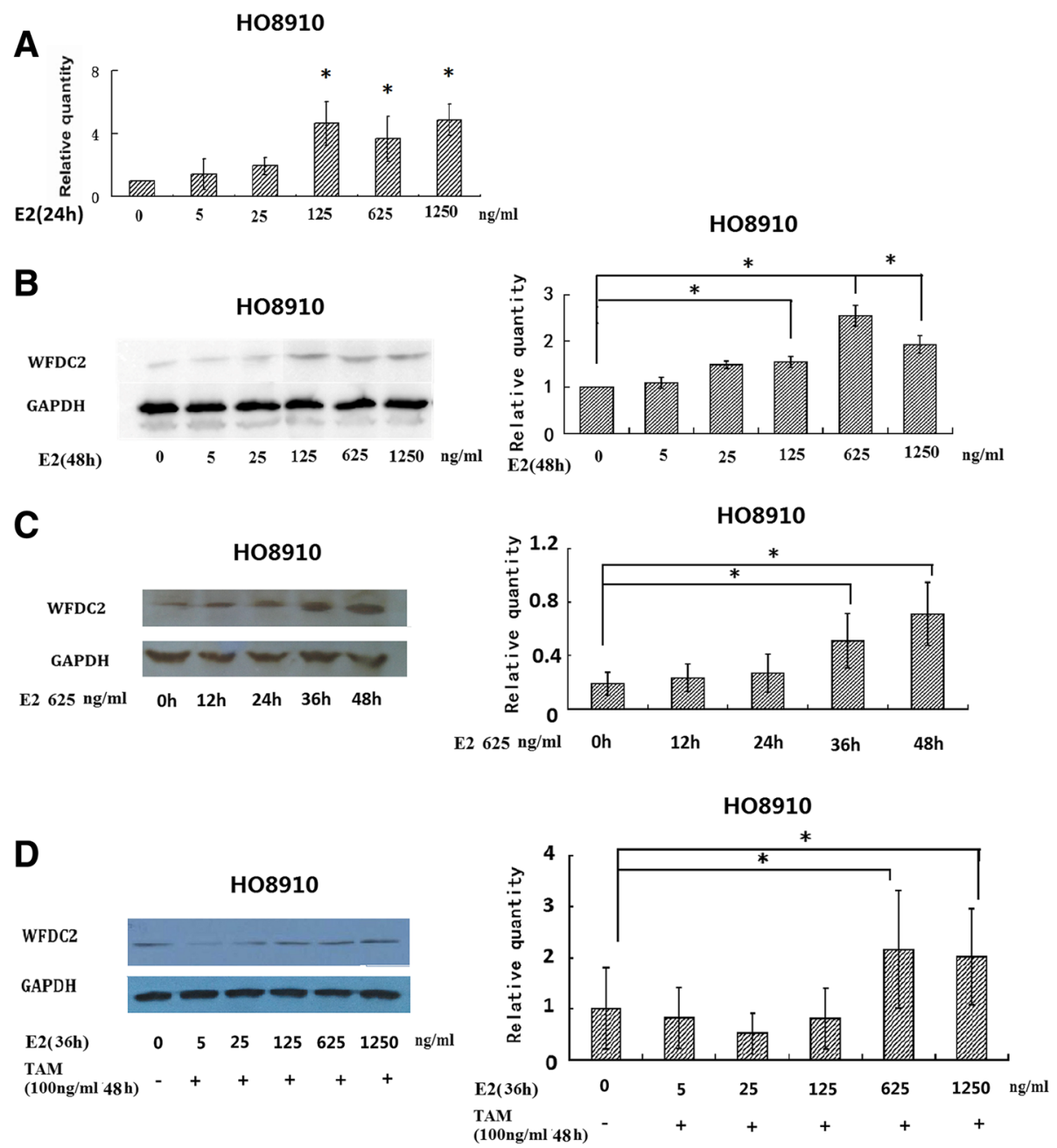

Fig. 1 E2 induces expression of WFDC2 in HO8910 cells. a Real-time RT-PCR analysis of the expression of WFDC2 and GAPDH in HO8910 cells after stimulation with E2 at different concentrations for $48 \mathrm{~h}(n=3)$. The relative amounts of WFDC2 protein were determined using densitometry and normalized to GAPDH. ${ }^{*} P<0.05$. $\mathbf{b}$ Western blot analysis of the expression of WFDC2 and GAPDH in HO8910 cells after stimulation with E2 at different concentrations for $48 \mathrm{~h}(n=3)$. The relative amounts of WFDC2 protein were determined using densitometry and normalized to GAPDH. ${ }^{*} P<0.05$ versus the solvent control. c Western blot analysis of the expression of WFDC2 and GAPDH in HO8910 cells after stimulation with $625 \mathrm{ng} / \mathrm{ml}$ E2 at different time points. $n=3,{ }^{*} P<0.05$ versus $0 \mathrm{~h}$. $\mathbf{d}$ Western blot analysis of the expression of WFDC2 and GAPDH in HO8910 cells incubated with TAM $(100 \mathrm{ng} / \mathrm{ml})$ for $8 \mathrm{~h}$ and then incubated with E2 $(625 \mathrm{ng} / \mathrm{ml})$ for $36 \mathrm{~h} . n=3,{ }^{*} P<0.05$ versus the control

level of WFDC2 by 2.54-fold. The effect of E2 on WFDC2 expression was not dose-dependent (Fig. 1c). After $24 \mathrm{~h}$ treatment, expression of WFDC2 was observed to be upregulated and the upregulation was sustained for over $48 \mathrm{~h}$ (Fig. 1c).

We next determined whether the ER signaling pathway regulated WFDC2 mRNA expression. SKOV3 ovarian carcinoma cells have functional ERs but are insensitive to estrogen [21]. We used SKOV3 cells to prove whether WFDC2 was induced by estrogen. A basal level of WFDC2 was detected in SKOV3 cells but protein expression was not induced by E2 (data not shown). HO8910 cells were incubated with TAM $(100 \mathrm{ng} / \mathrm{ml})$ for $8 \mathrm{~h}$ and then with E2 $(0,5,25,125,625$ and $1250 \mathrm{ng} / \mathrm{ml})$ for a further $36 \mathrm{~h}$. Cells were then harvested and expression of WFDC2 analyzed. Amounts of WFDC2 were increased by adding E2 to HO8910 cells and not affected by adding TAM (Fig. 1d).

These results indicated that WFDC2 was a downstream target of E2 but that regulation might not be through the ER $\alpha$ pathway.

\section{Knockdown of WFDC2 expression reduces cell proliferation driven by estrogen}

The dependence of WFDC2 expression on estrogen activity led us to study whether the proliferative growth of ovarian cancer cells induced by E2 was mediated by WFDC2. The sequence 209 shRNA, which was shown to 
effectively knock down the expression of WFDC2 in SKOV3 cells [12], was inserted into the retroviral vector and transduced into estrogen-sensitive HO8910 cells to produce the stable WFDC2 knockdown cell line (HO8910-209) (Additional file 1: Figure S1). Therefore, we compared the growth of HO8910-209 or SKOV3-209 cells with the negative control clone of each cell line to determine the role of WFDC2 both in estrogen-sensitive and estrogen-insensitive ovarian cancer cells.

Combined with previous results, knockdown of the expression of WFDC2 dramatically decreased the cell proliferation of both HO8910-209 and SKOV3-209 cells (Fig. 2a). Additionally, we performed growth assays with high-dose E2 $(625 \mathrm{ng} / \mathrm{ml})$ to analyze the effect of WFDC2 knockdown on E2-triggered proliferation. Addition of E2 further decreased proliferation of HO8910-209 cells and the relative estrogen response of this cell line was not changed significantly by WFDC2 knockdown (Fig. 2b). In contrast, addition of high-dose E2 had very little effect on cell proliferation of estrogenunresponsive SKOV3 cells, while the growth of SKOV3209 cells was inhibited significantly by high-dose E2 compared with the SKOV3-NA cells. These results indicated that WFDC2 knockdown might transform the estrogen-unresponsive SKOV3 cells from a hormoneindependent to an estrogen-responsive phenotype (Fig. 2b). This transformation of ovarian cancer cells from a hormone-independent to an estrogen-responsive phenotype using knockdown of a single gene was further validated in proliferation experiments combining E2 with the SERM, TAM [22].

In estrogen-sensitive HO8910 cells, treatment with TAM resulted in the expected anti-proliferative effect on this cell line, which was also enhanced by WFDC2 knockdown (Fig. 2c). Compared with HO8910 cells, treatment with TAM $(100 \mathrm{ng} / \mathrm{ml})$ did not affect the growth of SKOV3 cells significantly. While knockdown of WFDC2 in this cell line enabled a strong inhibitory effect of TAM on E2-triggered growth of 65\% after 5 days of treatment (Fig. 2c), this drug did not significantly affect the growth of negative control SKOV3 cells.

Thus, the results indicated that knockdown of WFDC2 not only increased the sensitivity of ovarian cancer cells to the growth inhibition induced by high-dose E2, but
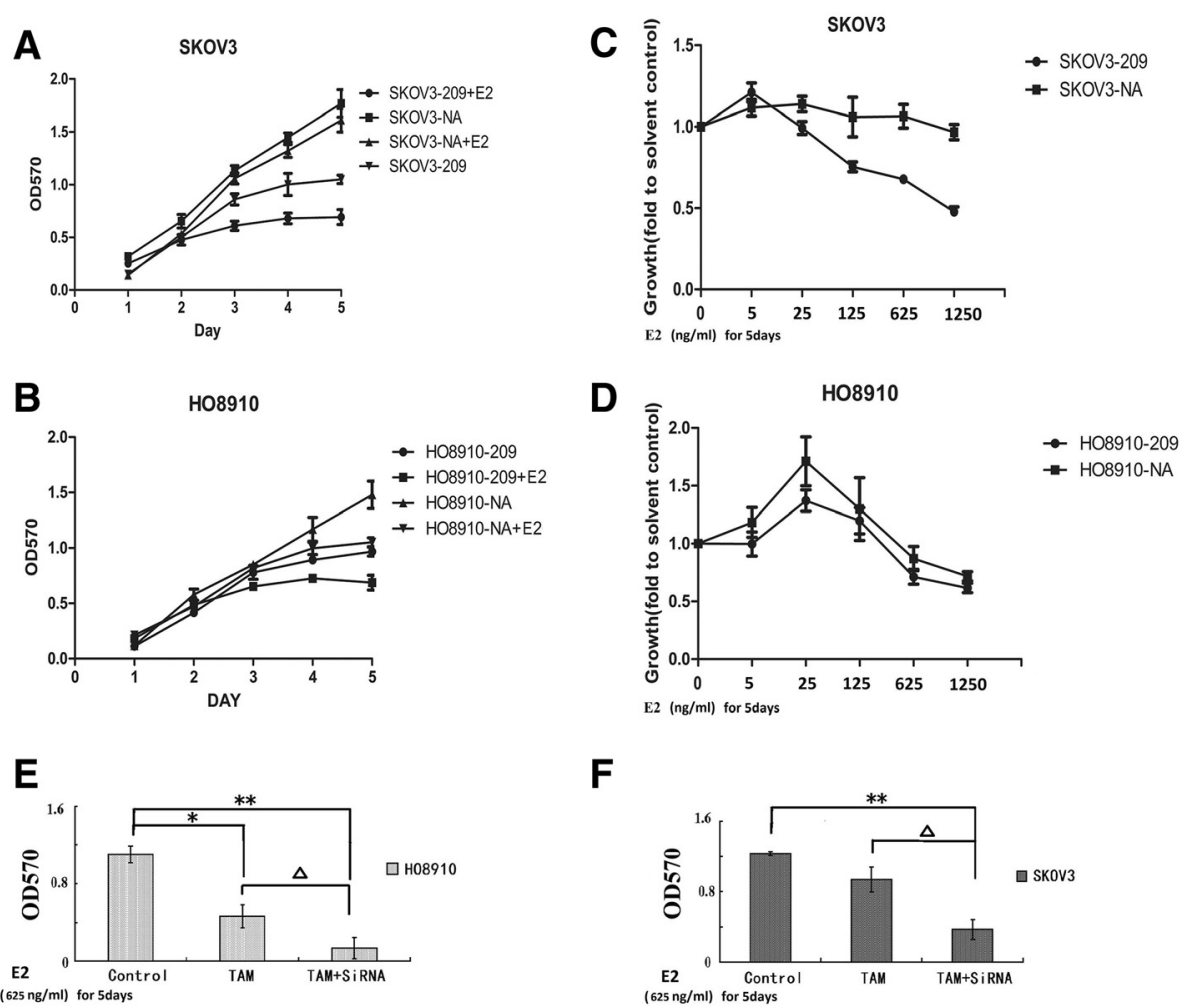

Fig. 2 Knockdown of WFDC2 expression reduces cell proliferation and enables an E2 response in SK-OV-3 ovarian cancer cells. HO8910 (a) or SKOV-3 (b) cells were treated with or without E2 $(625 \mathrm{ng} / \mathrm{ml})$ and knockdown of WFDC2 reduced the viable cell number compared with the negative control. $n=3{ }^{*} P<0.05$; ${ }^{*} P<0.01$. E2 response of HO8910 (c) and SKOV3 (d) cells. Knockdown of WFDC2 enabled an E2 response in SK-OV-3 ovarian cancer cells. HO8910 (e) or SKOV-3 (f) cells were treated with E2 $(625 \mathrm{ng} / \mathrm{ml})$ alone or in combination with TAM $(100 \mathrm{ng} / \mathrm{ml})$, and knockdown of WFDC2 increased the inhibition efficiency in ovarian cancer cells by adding TAM compared with the control; ${ }^{*} P<0.05$, ${ }^{* *} P<0.01$ for TAM versus the control. $\triangle P<0.05$, verus cells treated with TAM without ShRNA interference 
also transformed the estrogen-unresponsive SKOV3 cells from a hormone-independent to an estrogen-responsive phenotype.

\section{WFDC2 knockdown promotes apoptosis induced by high- dose estrogen}

Since E2 was shown to inhibit ovarian cancer cell growth, we investigated whether high-dose hormone treatment induced apoptosis in ovarian cancer cells. In this study, we performed flow cytometry and annexin VFITC/PI staining to detect apoptosis of estrogenresponsive HO8910 cells and estrogen-unresponsive SKOV3 cells.

The influence on cell cycle of high-dose estrogen was limited, while cell apoptosis was significantly increased by E2 in both WFDC2-knockdown cells and the control group, particularly in WFDC2-knockdown cells (Fig. 3a).

As shown in Fig. 3c, the percentage of apoptotic HO8910-209 cells $[21.6 \%( \pm 6.24)]$ was significantly higher than that of HO8910-NA cells [12.4\% $( \pm 4.28)]$ when treated with E2 $(p<0.05)$. The same results were observed with SKOV3 cells (Fig. 3c). The percentage of apoptotic SKOV3-209 cells [16.2 \% ( \pm 7.2$)]$ was significantly higher than that of SKOV3-NA cells [9.6\% $( \pm 5.68)]$ when treated with E2 $(p<0.05)$. Thus, knockdown of WFDC2 expression in ovarian cancer cells increased cell apoptosis induced by high-dose E2 in both estrogen-sensitive and estrogen-insensitive cells.

\section{Knockdown of WFDC2 decreases expression of ER $\beta$ in HO8910 and SKOV3 cells}

Given that WFDC2 knockdown transformed a hormoneunresponsive ovarian cancer cell line in an estrogenresponsive one, we were eager to know how this would be reflected at the gene expression level. For this purpose, we studied expression of ER $\alpha$ and ER $\beta$.

As shown in Fig. 4a, knockdown of WFDC2 expression led to no change in the level of ER $\alpha$ mRNA in either HO8910 or SKOV3 cells. In contrast, expression of ER $\beta$ was strongly increased in both cell lines.

We then used flow cytometry to determine whether upregulation of ER $\beta$ expression occurred at the protein level. HO8910 cells exhibited very weak ER $\beta$ protein expression but both HO8910 and SKOV3 cells showed

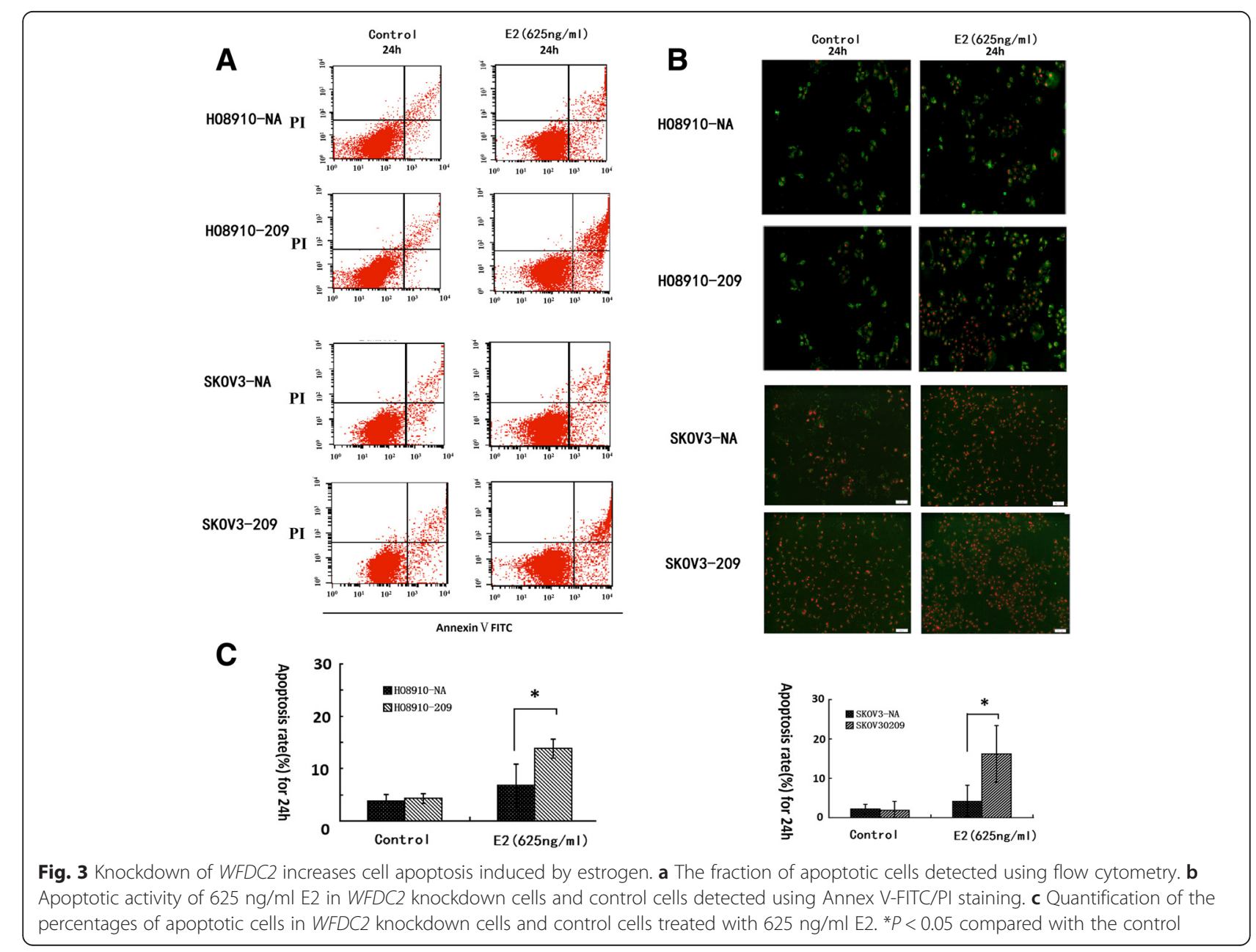




\section{A} ER $B$
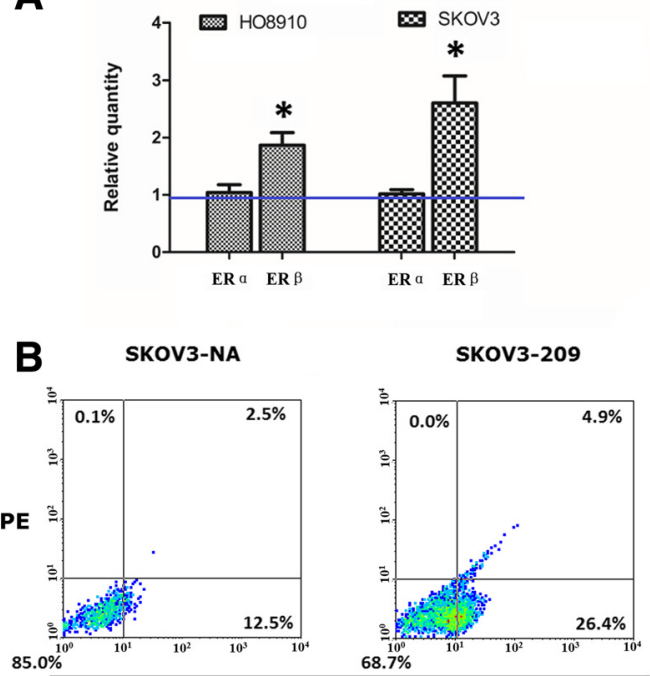

C

ER- $\beta$

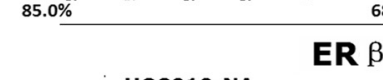

ER $\beta$
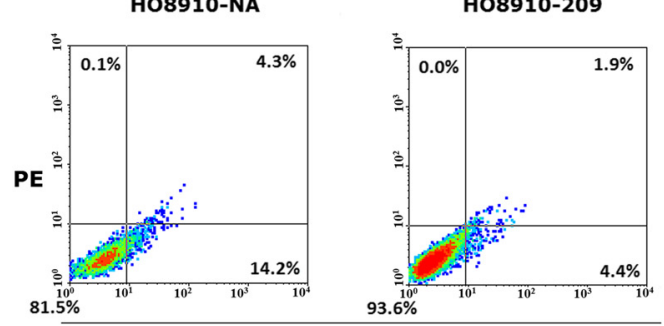
93

ER $\beta$
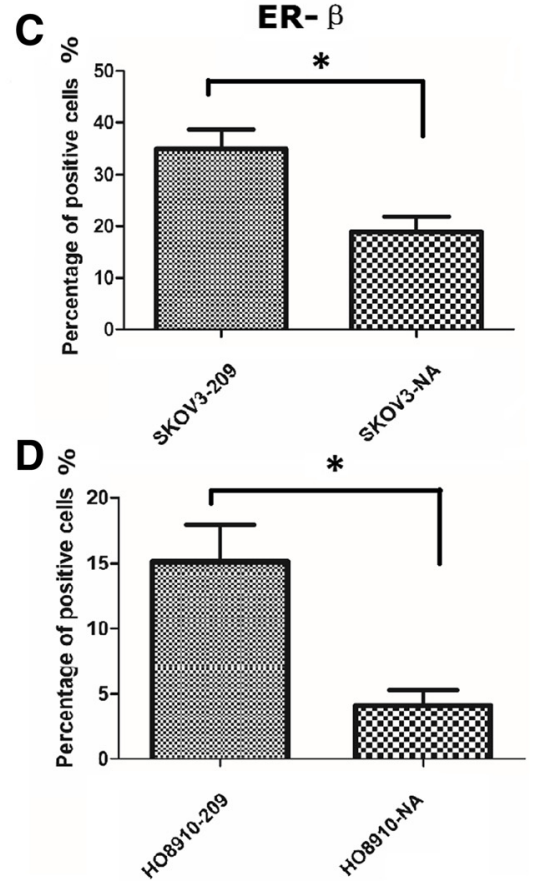

Fig. 4 Knockdown of WFDC2 increases expression of ERß in HO8910 and SK-OV-3 cells. a Normalized ERa and ERß RNA levels in WFDC2 knockdown cells and control cells using real-time RT-PCR. The relative quantities of ERa and ERß were determined using densitometry and normalized with GAPDH. ${ }^{*} P<0.05$ versus the control. b Flow cytometric graphs for ERß expression in WFDC2 knockdown cells and control cells. c Quantification of the percentages of ERß-positive cells in WFDC2 knockdown cells and control cells. ${ }^{*} P<0.05$ versus the control
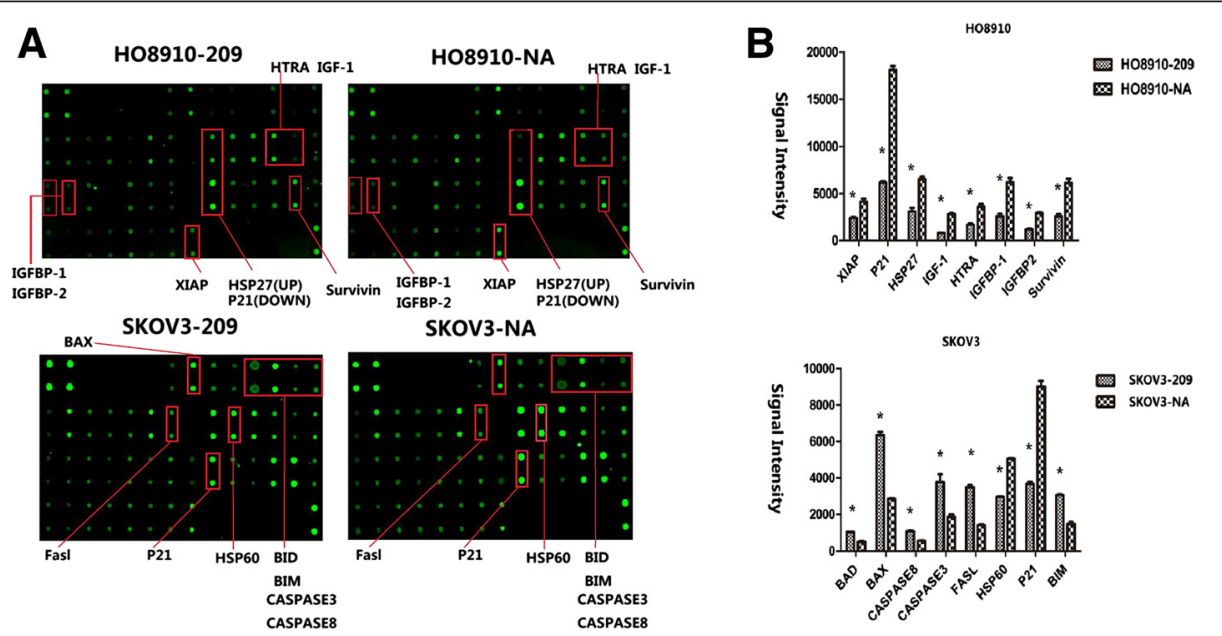

Fig. 5 Genes related to cell apoptosis induced by E2 were modified by WFDC2 knockdown. a Original figure of RayBio ${ }^{\oplus} \mathrm{Human}$ Apoptosis Antibody array. $\mathbf{b}$ Graph of gene expression detected using the Human Apoptosis Antibody array. ${ }^{*} P<0.05$ compared with the control 
upregulation of ER $\beta$ expression in WFDC2-knockdown cell lines. The percentage of positive cells with ER $\beta$ expression was higher in WFDC2-knockdown cells than in the negative control cells (Fig. 4b).

\section{WFDC2 regulates genes related to cell apoptosis under estrogen treatment}

To explore the molecular mechanisms, RayBio $^{\circ}$ Human Apoptosis Antibody array was used to screen protein expression of a range of apoptosis-related genes (Fig. 5a). Figure $5 \mathrm{~b}$ shows the protein microarray signal intensities for apoptotic-related genes in HO8910-NA and HO8910209 cells. Notably, the microarray intensities of HSP27, IGF-1, IGFBP, P21, HTRA, survivin and XIA were more highly suppressed in HO8910-209 than in HO8910-NC cells.

In hormone-unresponsive SKOV3 cells, we observed that the microarray protein intensities of Bad (Bcl-2 antagonist of cell death), Bax (Bcl-2 associated X protein), Bim (Bcl-2 interacting mediator), caspase 3 , caspase 8 and Fasl were higher, and the microarray intensities of P21 and Hsp60 were lower. Though the genes affected by WFDC2 knockdown were not identical in estrogensensitive HO8910 and estrogen-insensitive SKOV3 cells, using these data, we hypothesized that WFDC2 might represent a mechanism by which estrogen signaling induced cell apoptosis.

\section{Discussion}

Estrogen plays a crucial role in the control of development, sexual behavior and reproductive functions. Its effects have been linked to the progression of the majority of human ovarian cancers and acts as a potent mitogen for many ovarian cancer cell lines [3, 23]. In this study, we undertook to prove the hypothesis that WFDC2 is regulated by estrogen and that it might play a role in tumorigenesis induced by estrogen in ovarian cancer.

In this study, we demonstrated that high-dose E2 induced the upregulation of WFDC2 gene expression in estrogen-sensitive HO8910 cells, while no induction effect was observed in estrogen-insensitive SKOV3 cells. However, the estrogen selective inhibitor TAM could not block estrogen-induced WFDC2 expression. These results provide evidence of a positive relationship between WFDC2 expression and estrogen action; however, the regulatory effect might not be through the ER $\alpha$ pathway only, which will require further experiments to prove definitively.

This study also provides the first evidence for a functional role of the WFDC2 gene in the estrogendependent proliferation of ovarian cancer cells. It is generally considered that the proliferative effects of estrogen in cell culture occur at picomolar or nanomolar concentrations, typical levels in serum [1]. However, the ovary is an estrogen secretion organ, and thus micromolar concentrations of estrogen occur within the ovary and play a role in cell biology or transformation of normal ovarian surface epithelium and ovarian cancer cells, which has been largely overlooked [24, 25]. Proliferation in response to physiological concentrations of E2 has been reported in cultured ovarian cancer cells expressing ER, but currently there is no direct evidence in support of the hypothesis that high E2 levels present within the microenvironment of the ovary following ovulation contribute to the induction of ovarian cancer. Although physiological concentrations of estrogen can stimulate breast cancer cell proliferation, high-dose estrogens cause regression of some ER-positive human breast tumors.

In this study, we observed significant inhibition of cell growth induced by high-dose estrogen in estrogensensitive HO8910 cells, and a slight inhibition of cell growth in estrogen-insensitive SKOV3 cells. The suppression of the endogenous WFDC2 in ovarian cancer cells not only inhibited cell growth, but also significantly strengthened the response of estrogen-insensitive SKOV3 cells to estrogen. These data suggest the involvement of WFDC2 in estrogen signaling and in estrogenresponsiveness of ovarian cancer cells. We also found that WFDC2 knockdown could affect the hormonedependent proliferation not only in HO8910-sensitive but also in SKOV3-insensitive cells. WFDC2 knockdown decreased proliferation of SKOV3 ovarian cancer cells and, more strikingly, switched on a strong estrogen response in this estrogen-unresponsive cell line.

This transformation of ovarian cancer cells from hormone-independent to an estrogen-responsive phenotype by knockdown of a single gene was further validated in proliferation experiments combining E2 with TAM. As shown in the results, WFDC2-knockdown increased the sensitivity of cells to TAM not only in estrogen-sensitive, but also in estrogen-insensitive cells. The suppression of the endogenous WFDC2 in ovarian cancer cells was more likely suppressed by TAM. Thus, the specific role of WFDC2 in cell growth in the microenvironment with high-dose estrogen may be associated with ovarian epithelial cancer cell growth and transformation, and may also be involved in TAM resistance.

Previously, we demonstrated that the expression of WFDC2 promoted cell proliferation as well as $\mathrm{G} 1 / \mathrm{S}$ transition, while stimulating cyclin D1 expression [12]. Cyclin D1 has been confirmed as one of the estrogen target genes, and confers the mitogenic role of estrogen [26]. These results led us to postulate that WFDC2 participated in estrogen-dependent proliferation through regulating expression of cell cycle checkpoint proteins. While, no previous evidence has been presented, WFDC2 has been shown to be associated with cell 
apoptosis [12]. We further analyzed whether apoptosis, regulated by estrogen, could be affected by WFDC2 expression. Using FACS analysis, we showed that high concentrations of estrogen could significantly increase the level of cell apoptosis, and that loss of WFDC2 expression resulted in a significant increase in the rate of apoptosis under high-dose estrogen both in estrogensensitive and insensitive cells. Our results demonstrated that pharmacological concentrations of estrogen induced apoptosis in human ovarian cancer cells that involved WFDC2 expression.

ER has been considered to be an important regulator of estrogen-sensitive cell behavior. The response of neurons to estrogen depends on the ER subtype expressed in the cell. ER $\alpha$ is known to stimulate proliferation in response to estrogens by increasing expression of genes connected with cell cycle progression like cyclin D1 or growth factors, and by downregulating antiproliferative and proapoptotic genes [26, 27]. Lokich et al. demonstrated that WFDC2 interacted with $\mathrm{ER} \alpha$, and that WFDC2 overexpression resulted in ER $\alpha$ downregulation in ovarian cancer cells [19]. In our study, we did not observe upregulation of ER $\alpha$ in HO8910-209 cells; indeed, expression of ER $\alpha$ was almost unchanged by WFDC2 knockdown. While WFDC2 knockdown resulted in upregulation of ER $\beta$ in both HO8910 and SKOV3 cells. ER $\beta$ has been described to act as an antagonist of ER $\alpha$ in certain settings and to act as a tumor suppressor with proapoptotic and antiproliferative properties. Furthermore, loss of ER $\beta$ in ovarian epithelial cells has been linked to tumorigenesis and has been shown to increase proliferation of ovarian cancer cells $[6,28]$. A clear upregulation in the level of ER $\beta$ was noted in WFDC2knockdown cells, which could partially explain why high-dose estrogen caused more apoptosis in those cells. Thus, we hypothesize that upregulation of ER $\beta$ caused by suppression of WFDC2 is part of the mechanism underlying the decreased growth of these cells.

Because of these results, we further studied the correlation between WFDC2 and a series of genes that were related to cell proliferation and apoptosis using an apoptosis antibody array. In estrogen-sensitive HO8910 cells, insulin-like growth factor-1 (IGF-1) and insulin-like growth factor binding protein-1 and 2 (IGFBP-1 and IGFBP-2), which have been considered to be estrogenresponsive genes and related to the malignancy and metastasis of ovarian cancer [29-31], were downregulated in WFDC2-knockdown cells in the protein array. WFDC2 knockdown has also been shown to decrease HSP27 expression, which has also been identified as an estrogen-binding protein, playing a complex role in cell proliferation, migration and differentiation of estrogenresponsive tumors [32, 33]. X-linked inhibitor of apoptosis protein (XIAP) and survivin, apoptotic suppressors
[34-36], were also found to be downregulated in WFDC2-knockdown cells. These results are consistent with our previous hypothesis and explain the role of WFDC2 in estrogen-dependent cell proliferation and apoptosis induced by estrogen in ovarian cancer cells. However, not all the results were in line with our expectations. We expected, that the expression of tumor suppressor genes P21 [37] and HTRA [38, 39] should be increased by WFDC2 knockdown. But in fact, expression of these two genes in WFDC2-209 cells was significantly downregulated.

The results we observed in SKOV3 cells were also not entirely consistent with what we observed in the HO8910 cells. There was no evidence to confirm the relationship between WFDC2 and the insulin-like growth factor pathway, and we did not observe any change in IGFBP-A, IGF-1, HSP27 or XIAP in SKOV3 cells, although the data were of interest. It is well known that Bcl-2 family proteins are key regulators of apoptosis [40, 41], in particular, where involvement of the mitochondrial apoptotic pathway is concerned. In estrogeninsensitive SKOV3 cells, proapoptotic genes belonging to the Bcl2 family, such as Bad, Bax, and Bim were upregulated by WFDC2 knockdown. These data led us to suppose that WFDC2 could take part in cell apoptosis through the mitochondrial apoptotic pathway. Accordingly, proapoptotic genes, Fasl, Hsp60, caspase 3 and caspase 8 were also upregulated in WFDC2-knockdown cells, which also revealed the proapoptotic effects of WFDC2 knockdown. Additionally, the tumor suppressor gene P21 was downregulated in WFDC2-knockdown SKOV3-209 cells, and as seen in HO8910-209 cells. The contradictory results suggest that WFDC2 might be involved in a complex apoptotic net that will need further study to unravel.

The inconsistent results obtained using SKOV3 and HO8910 cells suggested that WFDC2 regulated cell apoptosis through different pathways in estrogensensitive and estrogen-insensitive cells. The focus of our upcoming research, therefore, will be to gain a better understanding of the relationship between WFDC2 and the insulin-like growth factor pathway to ascertain the role of WFDC2 on the physiological and pathological behavior of ovarian cancer. However, it was the downregulation of the tumor suppressor genes P21 and HTRA, which led us to question the pathophysiological role of WFDC2 in tumor initiation and progression. Understanding the detailed molecular mechanisms of action of WFDC2 in cell apoptosis induced with high-dose E2 will require further study.

\section{Conclusion}

In summary, understanding how estrogen is involved in ovarian cancer development and progression is important 
for determining strategies and targets for ovarian cancer prevention and treatment. For the first time, we, have identified WFDC2 as an estrogen target gene that might be involved in estrogen-induced physiological and pathological events. We also proved that WFDC2 affected tumor growth in the presence of high-dose estrogen through gene expression regulation, although further work on the specific mechanism is needed. Additional studies of WFDC2 could provide significant information as to its potential pathophysiological actions in ovarian cancer progression and might lead to novel strategies for tumor treatment in patients treated with anti-estrogens.

\section{Additional file}

Additional file 1: Figure S1. Expression of WFDC2 in SKOV3 cells silences clonal lines. (A) Western blot analysis of expression of WFDC2 and GAPDH in SKOV3 cells. Normalized WFDC2 protein levels in the shRNA-transfected (SKOV3-309, SKOV3-209), mock-transfected SKOV3-NA and control SKOV3 cells. The relative quantities of WFDC2 protein were determined by densitometry and normalized to GAPDH. ${ }^{*} P<0.05$ compared with SKOV3-NA; \#P<0.05 compared with SKOV3. (B) Western blot analysis of expression of WFDC2 and GAPDH in $\mathrm{HO} 8910$ cells. Normalized WFDC2 protein levels in shRNA-transfected and mock-transfected NA cells. Relative quantities of WFDC2 protein were determined using densitometry and normalized to GAPDH. ${ }^{*} P<0.05$ compared with HO8910-NA; (DOC 293 kb)

\section{Abbreviations}

WFDC2: WAP four-disulfide core domain 2; ERa/ß: estrogen receptor alpha/ beta; EMT: epithelial-mesenchymal transition; IHC: immunohistochemistry; qPCR: quantitative real-time PCR; NC: negative control; HRT: hormone replacement therapy; IGFBP: insulin-like growth factor binding protein; TFF: trefoil factor; FP: follicular; OP: ovulatory; E2: 17-ß-estradiol; SERM: selective ER modulator; TAM: tamoxifen.

\section{Competing interests}

The authors have no conflicts of interest to declare. All authors have approved the manuscript for publication.

\section{Authors' contributions}

Conceived and designed the experiments: YC, LTC, SHW, YSW, JLL and ML. Performed the experiments: YC, SHW, and LTC. Analyzed the data: YC, YSW, $J \mathrm{LL}$ and ML. Contributed reagents/materials/analysis tools: YC, LTC and SHW. Wrote the paper: YC, YSW, JLL and ML. All authors read and approved the final manuscript.

\section{Acknowledgments}

This work was supported by grants from the National High Technology Research and Development Program of China (863 Program) (No. 2012AA020205). This work was also supported by Guangzhou major collaborative innovation research projects (201508020052).

\section{Author details}

${ }^{1}$ School of Biotechnology, Southern Medical University, 1023 Shatainan Road, Guangzhou 510515, China. ${ }^{2}$ Molecular Oncology Laboratories, Department of Oncology, Weatherall Institute of Molecular Medicine, University of Oxford, Oxford OX3 9DS, UK.

Received: 30 September 2015 Accepted: 23 December 2015

Published online: 29 February 2016

\section{References}

1. Ho SM. Estrogen, progesterone and epithelial ovarian cancer. Reprod Biol Endocrinol. 2003;1:73.
2. Moore RG, Hill EK, Horan T, Yano N, Kim K, MacLaughlan S, et al. HE4 (WFDC2) gene overexpression promotes ovarian tumor growth. Sci Rep. 2014;4:3574

3. Gourley C. Hormone receptors and ovarian cancer survival. Lancet Oncol. 2013;14(9):794-5.

4. Haynes BP, Viale G, Galimberti V, Rotmensz N, Gibelli B, A'Hern R, et al. Expression of key oestrogen-regulated genes differs substantially across the menstrual cycle in oestrogen receptor-positive primary breast cancer. Breast Cancer Res Treat. 2013;138(1):157-65.

5. Hein A, Thiel FC, Bayer CM, Fasching PA, Haberle L, Lux MP, et al. Hormone replacement therapy and prognosis in ovarian cancer patients. Eur J Cancer Prev. 2013;22(1):52-8.

6. Treeck O, Pfeiler G, Mitter D, Lattrich C, Piendl G, Ortmann O. Estrogen receptor \{beta\}1 exerts antitumoral effects on SK-OV-3 ovarian cancer cells. J Endocrinol. 2007;193(3):421-33.

7. Sun P-m, Wei L-h, Sehouli J, Denkert C, Zhao D, Gao M, et al. [Role of estrogen receptor-related receptors alpha, beta and gamma in ovarian cancer cells]. Zhonghua Fu Chan Ke Za Zhi. 2005;40(8):544-8.

8. Zhao Z-N, Zhou Q, Bai J-X, Yan B, Qin W-W, Wang T, et al. Estrogen-induced dimerization and activation of ERalpha-fused caspase-8: artificial reversal of the estrogenic hormone effect in carcinogenesis. Cancer Biol Ther. 2011;11(9):816-25

9. Scott A, Weldon S, Taggart CC. SLPI and elafin: multifunctional antiproteases of the WFDC family. Biochem Soc Trans. 2011;39(5):1437-40.

10. Lu L, Katsaros D, Wiley A, de la Rigault Longrais IA, Risch HA, Puopolo M, et al. The relationship of insulin-like growth factor-II, insulin-like growth factor binding protein-3, and estrogen receptor-alpha expression to disease progression in epithelial ovarian cancer. Clin Cancer Res. 2006;12(4):1208-14

11. Sonnet E, Lacut K, Roudaut N, Mottier D, Kerlan V, Oger E. Effects of the route of oestrogen administration on IGF-1 and IGFBP-3 in healthy postmenopausal women: results from a randomized placebo-controlled study. Clin Endocrinol (Oxf). 2007;66(5):626-31.

12. Chen $Y, M u X$, Wang $S$, Zhao L, Wu Y, Li J, et al. WAP four-disulfide core domain protein 2 mediates the proliferation of human ovarian cancer cells through the regulation of growth- and apoptosis-associated genes. Oncol Rep. 2013;29(1):288-96.

13. Moore RG, Miller MC, Eklund EE, Lu KH, Bast Jr RC, Lambert-Messerlian G. Serum levels of the ovarian cancer biomarker HE4 are decreased in pregnancy and increase with age. Am J Obstet Gynecol. 2012;206(4):349. e1-7.

14. Bouchard D, Morisset D, Bourbonnais Y, Tremblay GM. Proteins with wheyacidic-protein motifs and cancer. Lancet Oncol. 2006;7(2):167-74.

15. Manolov V, Marinov B, Vasilev $V$, Andreeva A. [HE4-a new tumor marker for ovarian cancer]. Akush Ginekol (Sofiia). 2011;50 Suppl 2:11-5.

16. Moore RG, McMeekin DS, Brown AK, DiSilvestro P, Miller MC, Allard WJ, et al. A novel multiple marker bioassay utilizing HE4 and CA125 for the prediction of ovarian cancer in patients with a pelvic mass. Gynecol Oncol. 2009;112(1):40-6.

17. Zou SL, Chang XH, Ye X, Cheng HY, Cheng YX, Tang ZJ, et al. Effect of human epididymis protein 4 gene silencing on the malignant phenotype in ovarian cancer. Chin Med J (Engl). 2011;124(19):3133-40.

18. Chen $\mathrm{H} 1 \mathrm{HM}$, Adams JS. Control of estradiol-directed gene transactivation by an intracellular estrogen-binding protein and an estrogen response element-binding protein. Mol Endocrinol. 2008;22(3):559-69.

19. Lokich E, Singh RK, Han A, Romano N, Yano N, Kim K, et al. HE4 expression is associated with hormonal elements and mediated by importindependent nuclear translocation. Sci Rep. 2014;4:5500.

20. Anastasi E, Granato T, Marchei GG, Viggiani V, Colaprisca B, Comploj S, et al. Ovarian tumor marker HE4 is differently expressed during the phases of the menstrual cycle in healthy young women. Tumour Biol. 2010;31(5):411-5. doi:10.1007/s13277-010-0049-1.

21. Hua W, Christianson T, Rougeot C, Rochefort H, Clinton GM. SKOV3 ovarian carcinoma cells have functional estrogen receptor but are growth-resistant to estrogen and antiestrogens. J Steroid Biochem Mol Biol. 1995;55(3-4):279-89.

22. Braicu El, Chekerov R, Richter R, Pop C, Nassir M, Loefgren H, et al. HE4 expression in plasma correlates with surgical outcome and overall survival in patients with first ovarian cancer relapse. Ann Surg Oncol. 2014;21(3):955-62.

23. O'Donnell AJM, Macleod KG, Burns DJ, Smyth JF, Langdon SP. Estrogen receptor-alpha mediates gene expression changes and growth response in 
ovarian cancer cells exposed to estrogen. Endocr Relat Cancer. 2005;12(4):851-66.

24. Belin F, Goudet G, Duchamp G, Gerard N. Intrafollicular concentrations of steroids and steroidogenic enzymes in relation to follicular development in the mare. Biol Reprod. 2000;62(5):1335-43.

25. Fujiwara $T$, Lambert-Messerlian $G$, Sidis $Y$, Leykin $L$, Isaacson $K$, Toth $T$, et al. Analysis of follicular fluid hormone concentrations and granulosa cell mRNA levels for the inhibin-activin-follistatin system: relation to oocyte and embryo characteristics. Fertil Steril. 2000;74(2):348-55.

26. Felty $\mathrm{Q}$, Singh $\mathrm{KP}$, Roy D. Estrogen-induced G1/S transition of G0-arrested estrogen-dependent breast cancer cells is regulated by mitochondrial oxidant signaling. Oncogene. 2005;24(31):4883-93.

27. Frasor J, Gibori G. Prolactin regulation of estrogen receptor expression. Trends Endocrinol Metab. 2003;14(3):118-23.

28. Bardin A, Hoffmann P, Boulle N, Katsaros D, Vignon F, Pujol P, et al. Involvement of estrogen receptor beta in ovarian carcinogenesis. Cancer Res. 2004;64(16):5861-9.

29. Mahran YF, El-Demerdash E, Nada AS, Ali AA, Abdel-Naim AB. Insights into the protective mechanisms of tamoxifen in radiotherapy-induced ovarian follicular loss: impact on insulin-like growth factor 1. Endocrinology. 2013;154(10):3888-99.

30. Hwang K-A, Park M-A, Kang N-H, Yi B-R, Hyun S-H, Jeung E-B, et al. Anticancer effect of genistein on BG-1 ovarian cancer growth induced by 17 beta-estradiol or bisphenol A via the suppression of the crosstalk between estrogen receptor alpha and insulin-like growth factor-1 receptor signaling pathways. Toxicol Appl Pharmacol. 2013;272(3):637-46.

31. Grimberg $A 1 C P$. Role of insulin-like growth factors and their binding proteins in growth control and carcinogenesis. J Cell Physiol. 2000;183(1):1-9.

32. Song TF, Zhang ZF, Liu L, Yang T, Jiang J, Li P. Small interfering RNAmediated silencing of heat shock protein 27 (HSP27) Increases chemosensitivity to paclitaxel by increasing production of reactive oxygen species in human ovarian cancer cells (HO8910). J Int Med Res. 2009;37(5):1375-88.

33. Pai HC, Kumar S, Shen CC, Liou JP, Pan SL, Teng CM. MT-4 suppresses resistant ovarian cancer growth through targeting tubulin and HSP27. PLoS One. 2015;10(4):e0123819.

34. Miyamoto MTM, Iwaya K, Shinomiya N, Kato M, Aoyama T, Sasaki N, et al. Xchromosome-linked inhibitor of apoptosis as a key factor for chemoresistance in clear cell carcinoma of the ovary. $\mathrm{Br} J$ Cancer. 2014;110(12):2881-6.

35. Obexer PAM. X-linked inhibitor of apoptosis protein - a critical death resistance regulator and therapeutic target for personalized cancer therapy. Front Oncol. 2014;28(4):197. 1-9.

36. Zhu J, Lu X, Hua K-Q, Sun H, Yu Y-H, Feng Y-J. Oestrogen receptor alpha mediates 17beta-estradiol enhancement of ovarian cancer cell motility through up-regulation of survivin expression. Arch Gynecol Obstet. 2012;286(3):729-37.

37. Suzuki H, Emi M, Komiya A, Fujiwara Y, Yatani R, Nakamura Y, et al. Localization of a tumor suppressor gene associated with progression of human prostate cancer within a 1.2 Mb region of 8p22-p21.3. Genes Chromosomes Cancer. 1995;13(3):168-74.

38. Zurawa-Janicka D, Skorko-Glonek J, Lipinska B. HtrA proteins as targets in therapy of cancer and other diseases. Expert Opin Ther Targets. 2010;14(7):665-79.

39. Chien J, Campioni M, Shridhar V, Baldi A. HtrA serine proteases as potential therapeutic targets in cancer. Curr Cancer Drug Targets. 2009;9(4):451-68.

40. Bansal N, Marchion DC, Bicaku E, Xiong Y, Chen N, Stickles XB, et al. BCL2 antagonist of cell death kinases, phosphatases, and ovarian cancer sensitivity to cisplatin. J Gynecol Oncol. 2012;23(1):35-42.

41. Thomadaki H, Scorilas A. BCL2 family of apoptosis-related genes: functions and clinical implications in cancer. Crit Rev Clin Lab Sci. 2006:43(1):1-67.

\section{Submit your next manuscript to BioMed Central and we will help you at every step:}

- We accept pre-submission inquiries

- Our selector tool helps you to find the most relevant journal

- We provide round the clock customer support

- Convenient online submission

- Thorough peer review

- Inclusion in PubMed and all major indexing services

- Maximum visibility for your research

Submit your manuscript at www.biomedcentral.com/submit
C Biomed Central 